\title{
Using community health workers to deliver a scalable integrated parenting program in rural China: A cluster-randomized controlled trial
}

\author{
Renfu Luo $^{\mathrm{a}}$, Dorien Emmers ${ }^{\mathrm{b}}$, Nele Warrinnier ${ }^{\mathrm{b}}$, Scott Rozelle ${ }^{\mathrm{c}}$, Sean Sylvia ${ }^{\mathrm{d}, *}$ \\ ${ }^{\text {a }}$ China Centre for Agricultural Policy (CCAP), School of Advanced Agricultural Sciences (SAAS), Peking University (PKU), Beijing, China \\ ${ }^{\mathrm{b}}$ LICOS, KU Leuven, Leuven, Belgium \\ ${ }^{\mathrm{c}}$ Freeman Spogli Institute for International Studies, Stanford University, Stanford, USA \\ ${ }^{\mathrm{d}}$ Department of Health Policy and Management, Gillings School of Global Public Health and the Carolina Population Center, University of North Carolina at Chapel Hill, \\ Chapel Hill, USA
}

A R T I C L E I N F O

Keywords:

Early childhood development Integrated parenting program Psychosocial stimulation Health promotion

Randomized controlled trial

Rural China

\begin{abstract}
A B S T R A C T
Inadequate care during early childhood can lead to long-term deficits in skill development. Parenting programs are promising tools for improving parenting practices and opportunities for healthy development. We implemented a non-masked cluster-randomized controlled trial in rural China in order to assess the effectiveness of an integrated home-visitation program that includes both psychosocial stimulation and health promotion at fostering development and health outcomes of infants and toddlers in rural China. All 6-18 month-old children of two rural townships and their main caregiver were enrolled. Villages were stratified by township and randomly assigned to intervention or control. Specifically, in September 2015 we assigned 43 clusters to treatment (21 villages, 222 caregiver-child dyads) or control (22 villages, 227 caregiver-child dyads). In the intervention group, community health workers delivered education and training on how to provide young children with psychosocial stimulation and health care (henceforth psychosocial stimulation and health promotion) during biweekly home visits over the period of one year. The control group received no home visits. Primary outcomes include measures of child development (i.e. the Bayley Scales of Infant and Toddler Development, third edition-or Bayley-III) and health (i.e. measures of morbidity, nutrition, and growth). Secondary outcomes are measures of parenting practices. Intention-to-treat (ITT) effects show that the intervention led to an improvement of $0 \cdot 24$ standard deviations (SD) [95\% CI 0.04 SD-0.44 SD] in cognitive development and to a reduction of $8 \cdot 1$ [95\% CI $3 \cdot 8-12 \cdot 4]$ percentage points in the risk of diarrheal illness. In addition, we find positive effects on parenting practices mirroring these results. We conclude that an integrated psychosocial stimulation and health promotion program improves development and health outcomes of infants and toddlers (6-30 month-old children) in rural China. Because of low incremental costs of adding program components (that is, adding health promotion to psychosocial stimulation programs), integrated programs may be cost-effective.
\end{abstract}

\section{Introduction}

250 million children below the age of five in low and middle income countries are currently at risk of not achieving their full developmental potential due to risk factors such as poverty, malnutrition and nonstimulating home environments (Engle et al., 2007; GranthamMcGregor et al., 2007; Black et al., 2017). The threat of large losses of human potential due to inequality of opportunity for children to develop healthily due to their circumstances during early childhood-the period when the neurobiological capacity for change in the foundations of the hierarchical processes of skill development and brain malleability is the highest-provides a strong economic and neurobiological rationale for investment in the developmental opportunities of disadvantaged children (Heckman, 2013). Caregivers can exert a major influence on child development and health (including nutrition) via provision of a nurturing and safe home environment with sufficient learning opportunities that is stable and sensitive to children's health needs (Ngure et al., 2014; Britto et al., 2017). This study aims to contribute to the intervention literature on the impact of parenting training on the developmental potential of disadvantaged populations. Over the past 15 years, efficacy trials of parenting training programs (henceforth, psychosocial stimulation and health promotion interventions) in low-

\footnotetext{
${ }^{*}$ Corresponding author. Department of Health Policy and Management, Gillings School of Global Public Health, University of North Carolina at Chapel Hill, 170 Rosenau Hall, CB 7400, 135 Dauer Drive, Chapel Hill, NC 27599-7400, USA.

E-mail address: sean.sylvia@unc.edu (S. Sylvia).
} 
and middle-income countries have provided evidence of short-term and long-term effects on d evelopment and health o utcomes. In the short run, parenting programs targeting psychosocial stimulation have consistently been linked to better cognitive development (Attanasio et al., 2014; Aboud and Yousafzai, 2015; Sylvia et al., 2018); health interventions (including those that primarily target nutrition) have been found to have positive but inconsistent effects on child cognitive development ( $\mathrm{R}$ ao et al., 2014), nutritional outcomes (e.g. anemia) (Grantham-McGregor et al., 2014; Aboud and Yousafzai, 2015; PérezEscamilla and Moran, 2017), and the incidence of diarrheal illness (Luby et al., 2018); and programs targeted at hygiene and sanitation (e.g. handwashing) have the potential to reduce child morbidity (Fewtrell et al., 2005; Mistry et al., 2012; Seguin and Zarazúa, 2015). In the long run, pioneering parenting training programs have been linked to lasting effects on a range of lifelong h uman capital o utcomes including academic attainment, earnings, responsible citizenship, and health later in life (Heckman and Kautz, 2014).

While the efficacy of parenting programs in low- and middle-income countries is well established, a significant p olicy c hallenge is how programs can be delivered cost-effectively and at scale. One suggested approach has been to integrate early childhood development (ECD) programs (that we label as 'psychosocial stimulation' programs in this study) with health programs (Gowani et al., 2014; Yousafzai et al., 2014; Hamadani et al., 2019). Integrated programs targeted at multiple risk factors have the potential to minimize the odds of developmental delay for disadvantaged populations, while they can be more cost-effective than single-objective programs (Richter et al., 2017). Integrating programs can lead to gains in cost-effectiveness b ecause o f complementarities among different $\mathrm{d}$ omains of $\mathrm{c}$ hild $\mathrm{d}$ evelopment and health (Attanasio et al., 2015a). Health has been identified as a particularly important input for cognition (Attanasio et al., 2015b). In addition, joint delivery of program components may facilitate cost-saving complementarities on the implementation side since the costs common to interventions (e.g., hiring parenting trainers and installing a monitoring system) can be shared. Similar arguments have been used to rationalize the practice of delivering health and nutrition programs through schools (Ran et al., 2016; Bundy et al., 2018). Systematic reviews of ECD interventions concluded that integrated psychosocial stimulation and nutrition (only) programs can maintain the effects of each program component, but the existence of additivities between stimulation and nutrition components is unsure (Hurley et al., 2016). Earlier home-visitation programs combined psychosocial stimulation with nutrition supplementation, but did not deliver a program to provide parents with information on child health more broadly defined (Grantham-McGregor et al., 2014; Hurley et al., 2016). To the best of our knowledge, large-scale empirical evidence on the effectiveness of programs integrating training on psychosocial stimulation with health promotion (through the provision of information services) does not exist.

In collaboration with the non-governmental organizations Save The Children Beijing and Save the Children Hong Kong, we aimed to assess the effectiveness of a $\mathrm{h}$ ome $\mathrm{v}$ isitation $\mathrm{p}$ rogram $\mathrm{c}$ ombining parental training of child psychosocial stimulation with training on child health promotion. In this study, child psychosocial stimulation refers to engagement in interactive caregiver-child activities that benefit cognitive and social-emotional skill development (e.g., reading books to child); and child health promotion refers to the provision and use of adequate and appropriate child nutrition, hygiene habits, and other health-promoting behavior (e.g., oral hygiene of infants) by the primary caregiver. The parenting training of both components was delivered by local community health workers.

This intervention study was implemented in rural China. Despite a spectacular rise in overall well-being in China over the past four decades, many rural children are still born and raised in poverty, which puts them at a large disadvantage as compared to children that grow up in more well-off urban areas. Approximately $46 \%$ and $55 \%$ of infants growing up in poor rural areas were found to be developmentally delayed by the age of 1 and 2, respectively (Wang et al., 2019). In line with international research findings, this high prevalence of developmental delay has been linked to insufficiently stimulating learning environments and poor health promotion, including poor feeding practices, in remote rural areas (Luo et al., 2017; Sylvia et al., 2018). For example, a large-scale field study showed that, respectively, no more than $9 \%$ and $18 \%$ of poor, rural Chinese one year olds were engaged in interactive caregiver-child reading activities or story-telling during the previous day (Wang et al., 2019). Moreover, a large fraction (more than $30 \%$ ) of them were found to be anemic according to the WHO definition of anemia (Luo et al., 2015). This high prevalence of micronutrient deficiency was linked to poor feeding practices such as the provision of an overly plain diet low in iron-rich foods (Luo et al., 2014). Finally, no more than $76.6 \%$ of the rural caregivers in a large-scale survey reported that they always washed hands after changing a diaper. Respectively, only $25 \cdot 1 \%$ and $51 \cdot 3 \%$ of the respondents reported that they would always use soap and running water for handwashing (Tao et al., 2013). The absence of certain parenting practices may at least partly be caused by the fact that rural Chinese caregivers have no access to standard-ofcare programs that are specifically designed to deliver information on psychosocial stimulation or child health. Lacking access to health services has been linked to a lower likelihood for caregivers' to seek care from a (trained) care provider for their children (Haque et al., 2019). This type of community disadvantage (i.e. lacking access to quality health services) was found to be negatively associated with physical development of children in rural China (Lei, 2017). Furthermore, the overall quality of primary care that is available in rural Chinese communities is poor (Sylvia et al., 2015).

On the basis of a literature review of common, but problematic parenting practices in rural China (Luo et al., 2014; Wang et al., 2019) and in other low-resource regions (Ngure et al., 2014; Britto et al., 2017), a structured curriculum was designed to address parenting practices related to psychosocial stimulation and health promotion, including nutrition. We postulate that the integrated intervention will benefit child development and health outcomes as a result of intervention-induced adjustments in parenting skills and practices.

\section{Methods}

\subsection{Study design}

We designed the intervention as a cluster-randomized controlled trial covering all 43 villages in two rural townships in Yunnan and Hebei Province, China. These two townships, one in each province, were selected in consultation with local authorities from a list containing all poor, rural townships in the respective provinces. We randomized at the village level to reduce the risk of contamination across experimental groups. The intervention was implemented for one year beginning in October 2015. Follow-up data were collected in late September/October 2016. Approval for the study was obtained from the provincial offices of the National Health Commission (NHC) in Yunnan and Hebei in 2017, and from the ethics committee of Stanford University (USA, number 25734) on October 26, 2012 and renewed annually.

\subsection{Participants}

Sample households were selected based on a list of all registered births in the selected clusters provided by the local office of the NHC. All children aged 6-18 months on September 15, 2015 were enrolled in the study together with their primary caregivers. On average, 10 children were enrolled in each cluster. The resulting baseline sample includes 449 caregiver-child dyads from 43 villages. Due to internal migration, $13.8 \%$ of the caregiver-child dyads attritted by September 2016. As a consequence, follow-up data were collected for 390 children 
living in 42 villages. The caregivers of all children gave oral informed consent before enrolment and baseline data collection. Using Zelen's randomized consent design, we sought participant consent conditional on the assigned treatment status (Zelen, 1979). All caregivers were asked to give their informed consent for data collection. Prior to the start of the intervention, caregivers assigned to the intervention group were then additionally asked to give consent for participation in the parenting intervention.

\subsection{Randomization and masking}

In September 2015 the clusters were randomly assigned to control and treatment within two strata (one township in Yunnan Province and another in Hebei Province) using a computerized random number generator. Though complete masking was not possible in this study, caregivers were unaware that they were involved in an experiment and control group households were unaware of the intervention.

\subsection{Procedures}

All children and caregivers residing in clusters of the intervention group were enrolled for a home-based parenting program targeting child psychosocial stimulation and health promotion. During each of the fortnightly home visits over the period of one year, community health workers trained caregivers on interactive caregiver-child activities and provided them with information on child health and nutrition. All interactive caregiver-child activities were stage-based and fully scripted in an ECD curriculum. This curriculum was loosely based on the curriculum developed for a pioneering parenting intervention in Kingston, Jamaica and adapted to Chinese settings by local child development psychologists and ECD experts (Sylvia et al., 2018). Each activity focused on one of the following four types of skills: cognition, language, motor, or social-emotional skills. During each bi-weekly visit two new skill-activities were introduced (that is, parents were given training in the activities) such that caregivers would encounter a new activity that was designed to promote each of the four targeted developmental skills each month.

During each visit, caregivers also received information on child health promotion through structured conversations about age-appropriate nutrition and health topics. These structured conversations were developed by experts of the Capital Institute of Pediatrics (CIP) of the Chinese Academy of Medical Sciences (CAMS). Nutrition topics included age-appropriate feeding practices, dietary diversity, meal frequency, and nutritional supplementation. Health information covered issues related to immunization, hygiene, and healthy eating and sleeping behavior. During each training session the child was measured and weighed. In cases where health workers observed deviating growth trajectories, important developmental delays or potentially serious illnesses, they would advise the caregiver to consult a medic.

Home visits were delivered by community health workers in service of the NHC. To provide the local health workers with necessary knowledge, skills and tools to deliver quality parenting training in psychosocial stimulation and health promotion, they received a copy of the fully-scripted ECD curriculum for instructions on interactive play activities, an ECD toolkit (including a growth chart, development check list, counselling materials and user handbook), and a manual with stage-based structured conversations on child health issues. In addition, all trainers ( $\mathrm{n}=36$, see Table 2$)$ participated in a one-week intensive training course on the basic theories of ECD and on communication, coaching and counselling skills taught by three ECD experts. The training program consisted of 5 days of classroom-based instruction in combination with 2 days of field p ractice. $\mathrm{F}$ ully-scripting the curriculum obviated the need for more extensive training of the community health workers, reducing overall program costs significantly.

To monitor service quality, a carefully designed supervisory system was set up and implemented by the government. First, the compliance of the community health care workers was tracked by a mobile app which requested the workers to log into at the start of each home visit. Second, county-level or township-level officials of the NHC randomly conducted unannounced supervision of a home visit of each instructor every 3 months and provided feedback and reinforcement training. Third, phone interviews were conducted to invite caregivers to give feedback on the quality of home visits. All intervention households received phone calls on a revolving basis. Every two months, a third of the enrolled primary caregivers in each village were called. Course content of the reinforcement training sessions was adjusted according to caregiver feedback.

\subsection{Outcomes}

Primary outcomes of interest are measures of child development and health, including the incidence of illness, nutrition and physical growth. First, child development was assessed at baseline (at 6-18 months) and follow-up (at 18-30 months) using the third edition of the Bayley Scales of Infant and Toddler Development (Bayley-III; Bayley, 2006). The four scales for cognition, language, motor, and socialemotional skill development of the Bayley-III questionnaire were translated into Mandarin Chinese and adapted to Chinese settings. Earlier versions of the Bayley scale have been used in China and reported in the papers of other research teams (Luo et al., 2015, 2017; Sylvia et al., 2018; Wang et al., 2019). The language scale consists of two subscales measuring receptive and expressive language development; the motor scale comprises the subscales of fine and gross motor skills. Bayley-III tests were administered at home by trained enumerators. All enumerators attended a one-week training course including 2.5 days of experiential learning in the field at baseline and follow-up. We use Bayley-III raw scores instead of normed composite scores to construct measures of early skill development. An official reference population distribution for normalization of Bayley-III scores has not been established for China yet, hence we standardize Bayley-III raw scores using the observed sample distribution of scores. Given that Bayley-III raw scores are increasing in age, we eliminated the age effect by internally standardizing raw scores within age (month) groups. This is done by first estimating age-conditional means and standard deviations using non-parametric regression and then using these estimated statistics to compute age-adjusted internal z-scores for each subscale. This non-parametric standardization procedure has the advantage that it is less sensitive to outliers and small sample sizes within age categories than parametric procedures (Attanasio et al., 2015a; Rubio-Codina, Araujo, Attanasio, Muñoz \& Grantham-McGregor, 2016).

Second, child nutritional status was evaluated based on hemoglobin $\mathrm{Hb}$ measures collected by finger prick blood tests. Third, child health outcomes were obtained by caregiver-reported survey answers of child health status undertaken by trained enumerators. The risk of diarrheal illness and respiratory tract infections were assessed based on caregiver-reported incidence of diarrheal illness and symptoms of respiratory tract infection, i.e. coughing or having a cold during the two weeks prior to the survey. Fourth, child height and weight were measured by trained enumerators. We used a scale to weigh children with minimal clothing. We did tared weighing of children below the age of two and children over age two who wouldn't stand still. Height was assessed with a child measure mat.

We further collected information on secondary outcomes that might mediate intervention effects on primary outcomes. Secondary outcomes of interest in this study are measures of parenting practices and parental beliefs related to child psychosocial stimulation and health promotion (e.g., ability to read books to child, engagement of caregiver in interactive play with child) and measures of health promoting feeding practices (e.g., provision of iron rich foods for child). All measures were collected during a comprehensive household interview questionnaire administered to each child's main caregiver. 


\subsection{Statistical analysis}

We calculated the target sample size to detect a $0 \cdot 25$ standardized effect on B ayley-III c ognition s cores - the m ain o utcome variable of interest. Based on evidence from an earlier field experiment (Sylvia et al., 2018), we assumed an adjusted intraclass correlation coefficient (ICC) of 0.01 and that baseline scores would account for $60 \%$ of the variation in scores at follow-up. We further assumed an average cluster size of 10 children of 6-18 months of age with a coefficient of variation of cluster sizes of 0.5. Based on these parameters, we calculated that we required 19 clusters $(\mathrm{n}=190$ children) per treatment group to detect an effect size of $0 \cdot 25 \mathrm{SD}$ at $80 \%$ power given a two-sided significance level of $0 \cdot 05$. Additional villages were enrolled to overpower the study and allow for potential attrition.

We conducted the statistical analysis using Stata version 14.2. We used an analysis of covariance (ANCOVA) model to estimate intention-totreat (ITT) effects of the intervention on our p rimary a nd secondary outcomes. We used the most parsimonious model, where we regressed the outcome variables on an indicator that takes the value of 1 if the household was assigned to the intervention group and the value of 0 otherwise, the baseline value of the outcome variable, and stratum (township) fixed effect. Enumerator fixed effects were included for estimation of ITT effects on Bayley-III scores. All individuals $(n=390)$ with baseline and endline data were included in the analysis. P-values reported refer to two-tailed tests for the impact of the intervention.

Given multiple outcomes, we account for multiple hypothesis testing in the analysis. In order to limit the probability of falsely rejecting a test, we aggregate outcome measures within each domain into a summary index and estimate ITT effects on these summary indices (Fitzsimons et al., 2016). Each index is computed as a weighted mean of the standardized values of the outcome variables (with outcome variables re-defined such that higher values translated into a more desirable outcome). This summary index is an efficient Generalized Le ast Squares (GLS) estimator. The GLS weights are calculated to maximize efficiency by giving less weighted to outcomes that are highly correlated with each other, while outcomes that are uncorrelated and thus contain new information receive more weight. To obtain meaningful ITT estimates, we internally standardize the summary indices within age (month) group. This trial is registered with the ISR CTN registry, number ISRCTN72589193.

\subsection{Role of funding source}

The National Science Foundation of China (grant No. 71873008), the Data Center of Management Science NSFC-PKU (grant No. 2017KEY04) and Save the Children Hong Kong financed the trial. The National Science Foundation of China, the Data Center of Management Science NSFC-PKU and Save the Children Hong Kong had no role in study design, data collection, data analysis data interpretation, or writing of the report. Save the Children Beijing was involved in management and monitoring of the trial. The corresponding author had full access to all the data in the study and had final responsibility for the decision to submit for publication.

\section{Results}

Baseline data were collected between September 15 and October 15, 2015. 43 clusters were stratified by township and randomly assigned to intervention (21 clusters, 222 caregiver-child dyads) or control (22 clusters, 227 caregiver-child dyads; Fig. 1). 59 children (27 in intervention group, 32 in control group) were lost to follow-up. 390 children (190 in intervention group, 200 in control group) with follow-up data collected between September 15 and October 15, 2016 were included in the intention-to-treat analysis.

Table 1 shows descriptive statistics on child development, health, nutrition, and growth at baseline. $29 \cdot 7 \%$ of the baseline sample didn't achieve a Bayley-III composite cognition score of 92 - the age-appropriate cut-off score for cognitive delays (Wang et al., 2019). Descriptive statistics on baseline demographics, parenting skills and practices are shown in Tables A1-A3, respectively, of the online appendix. These tables also include tests for balance across the control and intervention arms. Differences across most of the individual characteristics are insignificant. An omnibus test across all baseline covariates (in Table 1 and Tables A1-A3) shows that the two groups are well balanced at baseline. We test this by regressing treatment status on the baseline characteristics and testing whether the coefficients were jointly equal to zero (p-value $=0.301)$. After accounting for attrition, our sample remains balanced (see Table A4). Table 2 gives an overview of the realisation and completion of intervention activities.

We find that the integrated parenting intervention had a significant effect on the summary index of skill development (effect size 0.17 SD, 95\% CI 0.02 SD-0.33 SD, see Table 3 and Fig. 2). We further find that the effect on the summary index was largely driven by the effect on cognitive development. The estimated ITT effect of the intervention on Bayley-III cognition scores was 0.24 SD [95\% CI 0.04-0.44]. We find no effect on (receptive or expressive) language, (gross or fine) motor or social-emotional development that is significantly different from zero. Second, we find that the intervention improved overall caregiver-reported child health (effect size 0.29 SD, CI 95\% 0.13 SD-0.46 SD). The intervention led to a reduction of $8 \cdot 1$ [95\% CI 3.8-12.4] percentage points in the risk that the child had an episode of diarrhea during the two-week period prior to the survey. We find no significant effect on the number of times the child was ill during the past two weeks or the probability that the child displayed symptoms of respiratory tract infection over the past two weeks.

The effects on child development and health may have been mediated by adjustments in parenting practices. First, we find that the intervention led to a significant improvement in parenting beliefs and practices related to child psychosocial stimulation (see Table A5). The parenting program led to an increase in the summary index of positive caregiver beliefs towards psychosocial stimulation (effect size 0.25 SD, 95\% CI 0.07 SD-0.44 SD) and the summary index of child cognitively stimulating parenting practices (effect size $0 \cdot 35$ SD, 95\% CI $0 \cdot 18$ SD$0 \cdot 52 \mathrm{SD}$ ). More specifically, with regards to caregiver beliefs, we find an increase of $11 \cdot 7$ [95\% CI 1.9-21.5] percentage points in the probability that a caregiver reported to know how to read to a child at the end of the intervention. Furthermore, with regard to the investment of caregivers in child psychosocial stimulation, we find that caregiver engagement in play activities with toys increased with 13.8 [95\% CI 1.7-25.9] percentage points. We also observe a significant increase in the probability that a child had its own play area in the household (effect size 11.3 percentage points, 95\% CI 3.3-19.4). Finally, we find a positive effect on the provision of an iron-rich diet for the child (effect size $0.23 \mathrm{SD}, 95 \%$ CI 0.01 SD-0.46 SD, see Table A6). We find no effect on the nutrition supplementation index.

\section{Discussion}

Using a cluster-randomized controlled trial, we assessed the effectiveness of an integrated parenting program that combined training of child psychosocial stimulation with training of child health promotion. First, we found a small to moderate effect size of 0.24 SD on standardized Bayley-III cognition raw scores. This indicates that the program maintained the positive effect size on cognitive skill development typically observed in the literature for single-objective psychosocial stimulation programs (Britto et al., 2017). Should the size of the effect on cognition scores found in this study be considered large? In fact, the impact on Bayley-III cognition scores found in this study (of 0.24 SD) is on par with previous intervention studies deemed highly successful, particularly in this field of education in developing countries (McEwan, 2012). Additionally, a $\mathbf{0} \cdot 24$ SD increase in standardized Bayley-III cognition scores is a sizeable effect for an ECD intervention delivered at 


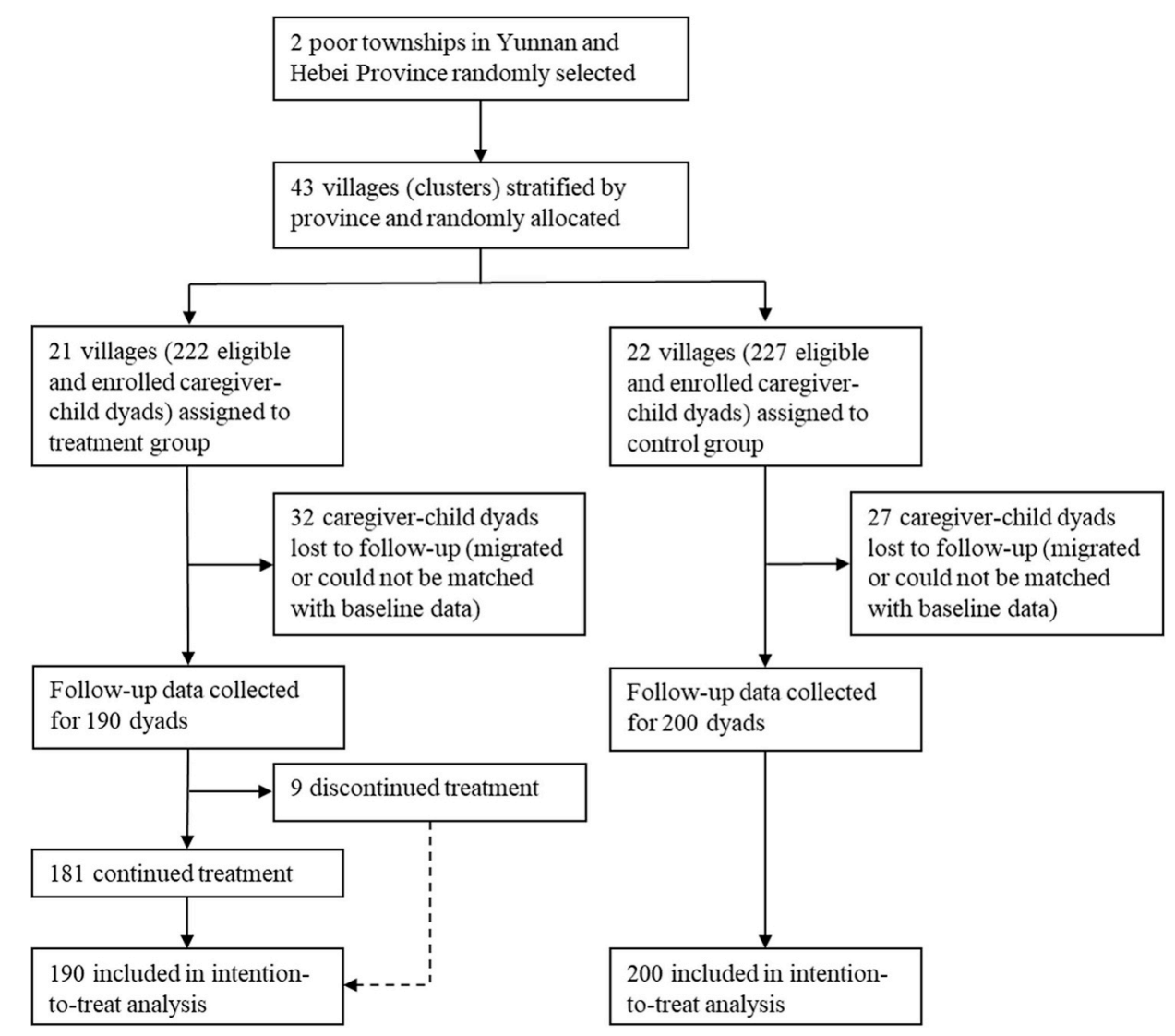

Fig. 1. Trial profile.

scale. Specifically, the effect size we detected is well in line with the effect of 0.26 SD and 0.27 SD observed in earlier home-based psychosocial stimulation interventions that were delivered to mimic an atscale intervention in Colombia and rural China, respectively (Attanasio et al., 2014; Sylvia et al., 2018). It is true that earlier parenting intervention studies found effect sizes that were larger. In our study (as well as in the studies of Attanasio et al. (2014) and Sylvia et al. (2018)), the authors opted to administer the Bayley test—which is widely viewed as the gold standard for assessment of ECD outcomes. The earlier studies that found higher measured impacts not only used other measures to assess ECD outcomes, they also had different designs (e.g., smaller sample sizes; designs to test efficacy rather than effectiveness) (Aboud and Yousafzai, 2019; Hamadani et al., 2019). Hence, it may be that these changes in study design may explain why smaller effects were observed on Bayley cognition scores in more recent at scale interventions as compared to in earlier studies.

Second, we found no significant effect on child nutrition or growth outcomes. On the one hand, this can be due to a rather limited impact of the intervention on caregivers' feeding behavior. We found a significant positive effect on the provision of an iron rich diet for the child, but not on overall dietary diversity or feeding frequency. On the other hand, considering the positive or insignificant effects on nutrition and growth outcomes observed in earlier single-objective nutrition interventions (Grantham-McGregor et al., 2014; Aboud and Yousafzai, 2015; Pérez-Escamilla and Moran, 2017), this finding of a null result is also not unexpected. The failure to find an effect on anemia is in line with findings from earlier nutrition interventions in rural China (Luo et al., 2017) and Colombia (Attanasio et al., 2014; Andrew et al., 2016). For example, an earlier large-scale home-based micronutrient supplementation intervention in rural China led to an improvement in hemoglobin levels after six months, but the researchers found no evidence indicating that the effect on anemia persisted one year after the end of the intervention (Luo et al., 2017). As argued by the authors of these papers, the absence of detectable effects of nutrition interventions on anemia in these regions may be caused by the changing nature of the causes of low hemoglobin levels and rapid natural decreases in anemia rates during the second year of life. The hemoglobin level in the control group of our sample increased approximately with ten milligrams per liter between baseline and follow-up. This contrasts to nutrition programs that were found to have a significant and positive effect on hemoglobin levels in other regions, where less rapid increases in the hemoglobin levels of the control group were observed (see, for example, Soofi et al. (2013)). The failure to find an effect on physical growth outcomes can also be explained by the low rates of growth failure among 0-3 year olds in rural China (Wang et al., 2018). In our sample, respectively, no more than $4.5 \%$ and $2.3 \%$ of the sample children were stunted and wasted (according to the WHO's Child Growth Standards). Moreover, it is possible that nutrition education programs are no effective tool to raise child physical growth in food secure regions. Systematic reviews found an uncertain impact of nutrition education interventions in food secure regions on child physical growth (Dewey and Adu-Afarwuah, 2008; Bentley et al., 2011; Lassi et al., 2013; GranthamMcGregor et al., 2014; Aboud and Yousafzai, 2015; Pérez-Escamilla and Moran, 2017). Finally, the failure to find an effect on growth in this study is strongly in line with Aboud et al. (2013) who also found no significant effect on the physical development of one-year olds as a result of an at scale integrated parenting program in rural Bangladesh.

Third, we observed a reduction in children's risk of diarrheal illness. Research on the effects of promoting changes in health-related parenting practices (e.g. handwashing and complementary feeding practices) indicates that health promotion interventions can lead to a reduction in the risk of influenza transmittable by hand, including diarrheal illness and respiratory tract infections, two main causes of morbidity and mortality among children below five (Fewtrell et al., 
Table 1

Baseline development, health, nutrition, and growth outcomes of intention-totreat population.

\begin{tabular}{|c|c|c|c|}
\hline & $\begin{array}{l}\text { Control } \\
(\mathrm{n}=227)\end{array}$ & $\begin{array}{l}\text { Intervention } \\
(\mathrm{n}=222)\end{array}$ & P-value \\
\hline \multicolumn{4}{|l|}{ Child development $^{\mathrm{b}}$} \\
\hline Cognition score & $41 \cdot 6(9 \cdot 0)$ & $40 \cdot 6(7 \cdot 9)$ & $0 \cdot 43$ \\
\hline Receptive language score & $14 \cdot 0(4 \cdot 4)$ & $13 \cdot 8(4 \cdot 0)$ & $0 \cdot 89$ \\
\hline Expressive language score & $14 \cdot 2(5 \cdot 3)$ & $13 \cdot 6(4 \cdot 9)$ & 0.53 \\
\hline Fine motor score & $28.9(5.7)$ & $28.8(5 \cdot 0)$ & $0 \cdot 75$ \\
\hline Gross motor score & $41 \cdot 0(10 \cdot 7)$ & $40 \cdot 6(9 \cdot 5)$ & $0 \cdot 86$ \\
\hline Social-emotional score & $69 \cdot 3(13 \cdot 5)$ & $68 \cdot 7(12 \cdot 5)$ & 0.99 \\
\hline \multicolumn{4}{|l|}{ Child health } \\
\hline \multicolumn{4}{|l|}{ Diarrhea in past month } \\
\hline Yes & $61(27 \%)$ & $46(21 \%)$ & $0 \cdot 21$ \\
\hline No & $166(73 \%)$ & $176(79 \%)$ & \\
\hline \multicolumn{4}{|c|}{ Symptoms of respiratory tract infection in past month } \\
\hline Yes & $130(57 \%)$ & $123(55 \%)$ & 0.96 \\
\hline No & $97(43 \%)$ & $99(45 \%)$ & \\
\hline $\begin{array}{l}\text { Number of times ill in past } \\
\text { month }\end{array}$ & $1.0(0.9)$ & $0.9(0.9)$ & $0 \cdot 30$ \\
\hline \multicolumn{4}{|l|}{ Child nutrition and growth } \\
\hline Hemoglobin $(\mathrm{g} / \mathrm{L})^{\mathrm{c}}$ & $\begin{array}{l}106 \cdot 6 \\
(95 \cdot 0-118 \cdot 0)\end{array}$ & $107 \cdot 2(98 \cdot 0-117 \cdot 0)$ & 0.93 \\
\hline \multicolumn{4}{|l|}{ Anemic ${ }^{c}$} \\
\hline Yes & $120(54 \%)$ & $118(56 \%)$ & 0.51 \\
\hline No & $102(46 \%)$ & $94(44 \%)$ & \\
\hline Height $(\mathrm{cm})^{\mathrm{a}}$ & $76 \cdot 2(72 \cdot 5-80 \cdot 0)$ & $75 \cdot 6(72 \cdot 0-79 \cdot 0)$ & $0 \cdot 48$ \\
\hline Weight $(\mathrm{kg})^{\mathrm{a}}$ & $9 \cdot 7(8 \cdot 7-10 \cdot 7)$ & $9 \cdot 6(8 \cdot 6-10 \cdot 4)$ & 0.91 \\
\hline Weight for age $\mathrm{e}^{\mathrm{a}}$ & $0 \cdot 16(1.08)$ & $0 \cdot 11(1 \cdot 14)$ & $0 \cdot 76$ \\
\hline \multicolumn{4}{|l|}{ Underweight $^{\mathrm{a}}$} \\
\hline Yes & $10(4 \%)$ & $5(2 \%)$ & $0 \cdot 13$ \\
\hline No & $213(96 \%)$ & $211(98 \%)$ & \\
\hline Length for age $\mathrm{e}^{\mathrm{a}}$ & $0.24(1.22)$ & $0.03(1.36)$ & $0 \cdot 30$ \\
\hline Weight for length ${ }^{a}$ & $0 \cdot 10(1 \cdot 16)$ & $0 \cdot 15(1.13)$ & $0 \cdot 33$ \\
\hline
\end{tabular}

Data are mean (SD), n (\%), or median (IQR). 'Anemic' is a dummy variable = 1 if altitude-adjusted hemoglobin concentration $<110 \mathrm{~g} / \mathrm{L}$. 'Underweight' is a dummy variable $=1$ if child's weight-for-age z-score is more than two SD below the mean of the WHO reference population. P-values for difference in means across control and intervention group are adjusted for clustering at the village level.

a Height and weight are missing for 9 children.

b Expressed in Bayley-III raw scores. Baseline Bayley-III scores are missing for 1 child.

c Hemoglobin values are missing for 15 children at baseline.

Table 2

Intervention activities.

\begin{tabular}{ll}
\hline & Number \\
\hline Eligible children & 449 \\
Trained parenting instructors & 36 \\
Total number of home visits & 3387 \\
Average number of home visits per household & $15 \cdot 3$ \\
\hline
\end{tabular}

2005; Mistry et al., 2012; Seguin and Zarazúa, 2015; Luby et al., 2018). A systematic review of non-clinical interventions found that changing health-related parenting practices can lead to a reduction in the risk of diarrheal illness ranging from 13.3 to 61.0 percentage points among children in developing countries (Seguin and Zarazúa, 2015). This means that the effect of 8.1 percentage points observed in our study is comparatively small. This study is the first intervention study conducted in rural China that relates education on nutrition and health to a reduction in the risk of influenza transmittable by hand.

In terms of mechanisms, we find evidence that the effects on primary outcomes may have been mediated by improved parenting practices. This argument is supported by our finding of positive intervention effects on parenting beliefs and practices related to psychosocial stimulation. This finding is in line with earlier studies showing that enriching the home learning environment with more interactive play activities and materials can be a promising trajectory for promotion of ECD (Attanasio et al., 2014; Sylvia et al., 2018). We observed a positive adjustment in caregivers' feeding practices. More specifically, we found that caregivers in the intervention group provided, on average, a more iron-rich diet for the child. Our findings on parental behavior change are well in line with Aboud et al. (2013) who detected positive intervention effects of an integrated parenting training program in rural Bangladesh on cognitively stimulating parenting practices and child dietary intake. Findings on the importance of good parenting practices will be disseminated as they may contribute to the spread of better parenting practices in the long run.

Finally, this integrated psychosocial stimulation and health promotion parenting program has the potential to be cost-effective and scalable. Cost-effectiveness comparisons are not straightforward due to incomparability of evidence across programs stemming from differences in data availability, data quality, duration of treatment, frequency of home-visits, length of follow-up, and other situational characteristics. Moreover, implementing parenting programs for a fine-grained comparative cost-effectiveness analysis comes at a very high cost. As a consequence, evidence on the cost-effectiveness of parenting training programs is very scarce. An exception was an intervention study in rural Pakistan showing that integrated parenting curricula combining nutritional supplementation with stimulation can be more cost-effective than mere nutrition or stimulation curricula separately (Gowani et al., 2014). In-depth comparative cost-effectiveness analyses are needed to guide policy makers interested in the scaling up of parenting programs. In this study, we do not have sufficient data to conduct such analysis. However, considering that the program produced gains across different domains, we argue that integration of program components can produce significant cost savings relative to single-objective programs as long as the incremental cost of adding a program component is low.

The strengths of this study include the application of a carefully developed parenting curriculum and data collection of a comprehensive set of child development and health outcomes. However, our study also faces several limitations. First, the study took place in only two townships in two Chinese provinces. Second, we estimated ITT effects at one point in time. Longer-run follow-up of sample children will be necessary to determine whether the observed gains will persist over time. Third, in the absence of clinically assessed health measures, we measured child health using caregiver-reported health-status questions. Fourth, approximately $13 \cdot 1 \%(n=59)$ of children attritted from our sample between baseline and follow-up. This is unlikely to have significantly affected our estimates of program impact, however, given that attrition is balanced across experimental groups.

We also note that compliance to the intervention was relatively low. On average 15.3 visits out of 24 planned visits took place. To put this in perspective, on average 16.4 visits out of 24 planned visits were completed in an earlier psychosocial stimulation intervention in rural China (Sylvia et al., 2018). Low compliance may have attenuated the effects of the intervention. To examine how the effect of the program may improve with better compliance, we estimated the dose-response relationship between the number of visits completed and the main outcomes. Specifically, we used control functions to estimate relationships between the number of completed home visits and the summary indices of child development and health. We did this first assuming a linear relationship and then allowing for a concave relationship by adding a squared term for the number of completed household visits. We instrument the number of visits with treatment assignment, the distance from the home to the nearest center of the NHC, and the interaction between these two variables. As shown in Table A7, we find up to 26 household visits (full compliance) evidence for a linear relationship between the number of home visits and both of these indices. We estimated that each completed session increased child skill development scores by 0.010 SD [95\% CI 0.001-0.020] and child health scores by 0.019 SD [95\% CI 0.008-0.030]. As shown in columns (2) of Table A7, we didn't find empirical evidence for concavity in the dose-response 
Table 3

Estimated effects of intervention on child development, health, nutrition, and growth.

\begin{tabular}{|c|c|c|c|c|}
\hline \multirow[t]{2}{*}{ Outcomes } & \multicolumn{3}{|c|}{ Intervention } & \multirow{2}{*}{$\begin{array}{l}\text { Mean of control group } \\
\text { at follow-up }\end{array}$} \\
\hline & No. & $\beta(95 \% \mathrm{CI})$ & P-value & \\
\hline \multicolumn{5}{|l|}{ Panel A: Skill development } \\
\hline Summary index ${ }^{\mathrm{a}}$ & 385 & $0.17(0.02-0 \cdot 33)$ & 0.04 & -0.08 \\
\hline Cognition score & 386 & $0.24(0.04-0.44)$ & $0 \cdot 01$ & $-0 \cdot 11$ \\
\hline Receptive language score & 386 & $-0.01(-0.17-0 \cdot 15)$ & $0 \cdot 89$ & -0.02 \\
\hline Expressive language score & 386 & $0.14(-0.03-0.32)$ & 0.09 & $-0 \cdot 04$ \\
\hline Gross motor score & 385 & $0 \cdot 14(-0 \cdot 04-0 \cdot 32)$ & $0 \cdot 12$ & -0.09 \\
\hline Fine motor score & 386 & $0 \cdot 13(-0.03-0 \cdot 29)$ & 0.09 & -0.06 \\
\hline Social-emotional score & 386 & $0 \cdot 10(-0 \cdot 07-0 \cdot 27)$ & $0 \cdot 24$ & $-0 \cdot 01$ \\
\hline \multicolumn{5}{|l|}{ Panel B: Health } \\
\hline Summary index ${ }^{\mathrm{a}}$ & 390 & $0 \cdot 29(0 \cdot 13-0 \cdot 46)$ & $0 \cdot 001$ & $-0 \cdot 15$ \\
\hline Diarrhea in past 2 weeks & 390 & $-0.08(-0.12--0.04)$ & $<0.001$ & $0 \cdot 12$ \\
\hline Symptoms of respiratory tract infection in past & 390 & $-0.08(-0.18-0.02)$ & $0 \cdot 10$ & 0.49 \\
\hline \multicolumn{5}{|l|}{2 weeks } \\
\hline Number of times ill in past 2 weeks & 390 & $-0.08(-0.23-0.07)$ & $0 \cdot 27$ & $0 \cdot 72$ \\
\hline \multicolumn{5}{|l|}{ Panel C: Nutrition and growth } \\
\hline Hemoglobin (g/L) & 367 & $-0 \cdot 22(-3 \cdot 96-3 \cdot 52)$ & $0 \cdot 91$ & $116 \cdot 5$ \\
\hline Anemic & 367 & $0 \cdot 01(-0 \cdot 11-0 \cdot 12)$ & 0.92 & $0 \cdot 27$ \\
\hline Summary index of physical growth ${ }^{\mathrm{a}}$ & 380 & $0.07(-0.08-0.22)$ & $0 \cdot 33$ & -0.03 \\
\hline Length/height for age & 380 & $0.01(-0 \cdot 16-0 \cdot 19)$ & $0 \cdot 87$ & -0.07 \\
\hline Healthy length/height for age & 380 & $0.02(-0.02-0.05)$ & $0 \cdot 36$ & 0.94 \\
\hline Healthy weight for height & 380 & $0.02(-0.03-0.07)$ & $0 \cdot 38$ & 0.92 \\
\hline Healthy weight for age & 380 & $-0.004(-0.04-0.03)$ & $0 \cdot 80$ & 0.93 \\
\hline
\end{tabular}

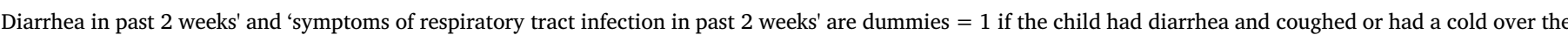

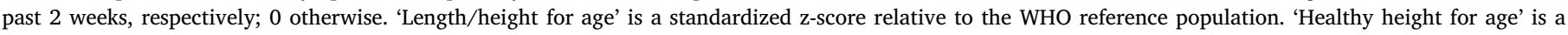

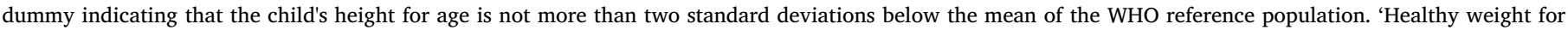

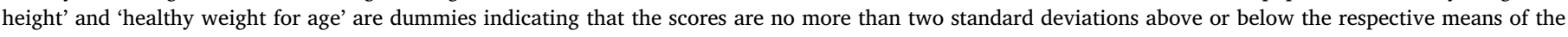
WHO reference populations.

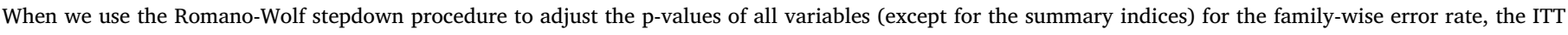
effects on cognition scores and the risk of diarrheal illness remain significant at the $5 \%$ level.

a The 'summary index' in panel A is the weighted average of the measures in rows 2-7. The 'summary index' in panel B is the weighted average of the absolute value of the measures in rows $2-4$ of panel B. The 'summary index' in panel C is the weighted average of the measures in rows $5-7$.

relationships. Assuming a linear relationship up to 26 household visits,

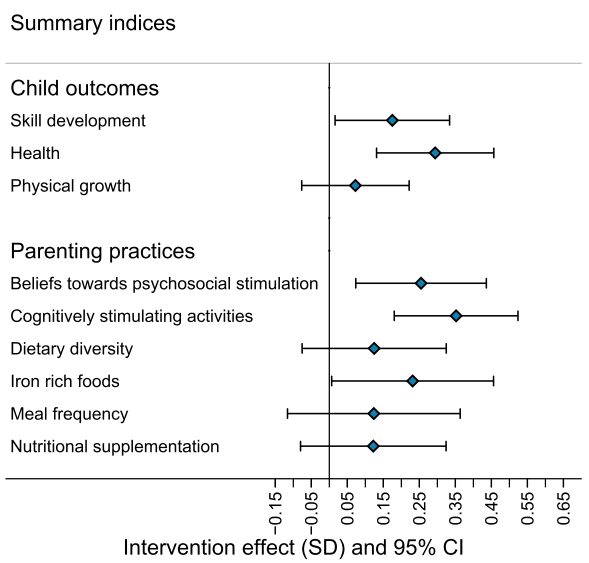

Fig. 2. Estimated effect of intervention on summary indices.

our estimates suggest that under full compliance skill development and health scores would on average have increased by 0.24 SD and 0.46 SD, respectively. These effects are larger than the estimated ITT effects (see Table 3). These estimates suggest that treatment effects of the intervention could increase with improved compliance, however, the ITT effects may better reflect the effect of the intervention at scale as noncompliance would likely occur in an at-scale program. Compliance has generally been found to be higher in shorter, more intense programs than in longer, less intense ones (Yousafzai and Aboud, 2014). Moreover, it is possible that this lower compliance rate as compared to the compliance rate in Sylvia et al. (2018) resulted in part from the longer duration of home visits due to the integration of two intervention components. Future studies should analyze whether home visit duration affects compliance and, if so, whether integrated programs can be delivered in a way that maintains high levels of compliance.

Our results provide evidence in favor of integration of multiple program components in early childhood home-visiting programs. We have shown that an integrated program with both psychosocial stimulation and health promotion can lead to improved outcomes across multiple domains. More specifically, we found that the home-based integrated parenting program: (1) maintained the positive effect on cognitive development found generally in single-objective psychosocial stimulation programs and (2) simultaneously led to an improvement in health as measured by a reduction in episodes of diarrheal illness. As long as the monetary benefits of a program component exceed the incremental costs associated with it, integration of the component in an existing program may lead to substantial gains in cost-effectiveness. Considering that offices of the NHC are present in all rural areas in China, parenting training on psychosocial stimulation and health promotion would be highly scalable when integrated with the existing service infrastructure of the NHC.

\section{Data sharing}

The de-identified data set and replication files are available from the Harvard Dataverse (https://doi.org/10.7910/DVN/XBGUUL).

\section{Contributors}

RL, SR, and SS developed the study concept and design; RL oversaw fieldwork and data collection; RL, NW, and DE analyzed the data; RL, SS, NW, and DE interpreted the results; DE and NW drafted the paper. 
SS, SR, NW, and DE had primary responsibility for review and editing of the final content. All authors read and approved the final version of the manuscript for publication.

\section{Declaration of interests}

All authors completed the ICMJE uniform disclosure form and declare no competing interests.

\section{Appendix A. Supplementary data}

Supplementary data to this article can be found online at https:// doi.org/10.1016/j.socscimed.2019.112545.

\section{References}

Aboud, F.E., Yousafzai, A.K., 2015. Global health and development in early childhood. Annu. Rev. Psychol. 66, 433-457.

Aboud, F.E., Yousafzai, A.K., 2019. Scaling up child psychosocial stimulation programmes for young children. Lancet Glob. Health 7 (3), e294-e295.

Aboud, F.E., Singla, D.R., Nahil, M.I., Borisova, I., 2013. Effectiveness of a parenting program in Bangladesh to address early childhood health, growth and development. Soc. Sci. Med. 97, 250-258.

Andrew, A., Attanasio, O., Fitzsimons, E., Rubio-Codina, M., 2016. Why is multiple micronutrient powder ineffective at reducing anaemia among 12-24 month olds in Colombia? Evidence from a randomised controlled trial. SSM-Populat. Health 2, 95-104.

Attanasio, O., Fernández, C., Fitzsimons, E., Grantham-McGregor, S.M., Meghir, C., Rubio-Codina, M., 2014. Using the infrastructure of a conditional cash transfer program to deliver a scalable integrated early child development program in Colombia: cluster randomized controlled trial. BMJ 349, g5785.

Attanasio, O., Cattan, S., Fitzsimons, E., Meghir, C., Rubio-Codina, M., 2015a. In: Estimating the Production Function for Human Capital: Results from a Randomized Control Trial in Colombia (NBER Working Paper No. w20965), Retrieved from. https://www.nber.org/papers/w20965.

Attanasio, O., Meghir, C., Nix, E., 2015b. In: Human Capital Development and Parental Investment in India (NBER Working Paper No. w21740), Retrieved from. https:// www.nber.org/papers/w21740.

Bayley, N., 2006. Bayley Scales of Infant Development, third ed. Psychological Corporation, San Antonio, TX.

Bentley, M.E., Wasser, H.M., Creed-Kanashiro, H.M., 2011. Responsive feeding and child undernutrition in low- and middle-income countries. J. Nutr. 141, 502-507.

Black, M.M., Walker, S.P., Fernald, L.C., Andersen, C.T., DiGirolamo, A.M., Lu, C., et al., 2017. Early childhood development coming of age: science through the life course. The Lancet 389 (10064), 77-90.

Britto, P.R., Lye, S.J., Proulx, K., Yousafzai, A.K., Matthews, S.G., Vaivada, T., et al., 2017. Nurturing care: promoting early childhood development. The Lancet 389 (10064), 91-102.

Bundy, D.A., de Silva, N., Horton, S., Jamison, D.T., Patton, G.C., 2018. Optimizing Education Outcomes: High-Return Investments in School Health for Increased Participation and Learning. World Bank, Washington, DC.

Dewey, K.G., Adu-Afarwuah, S., 2008. Systematic review of the efficacy and effectiveness of complementary feeding interventions in developing countries. Matern. Child Nutr. 4, 4-85.

Engle, P.L., Black, M.M., Behrman, J.R., De Mello, M.C., Gertler, P.J., Kapiriri, L., International Child Development Steering Group, 2007. Strategies to avoid the loss of developmental potential in more than 200 million children in the developing world. The Lancet 369 (9557), 229-242.

Fewtrell, L., Kaufmann, R.B., Kay, D., Enanoria, W., Haller, L., Colford Jr., J.M., 2005. Water, sanitation, and hygiene interventions to reduce diarrhoea in less developed countries: a systematic review and meta-analysis. Lancet Infect. Dis. 5 (1), 42-52.

Fitzsimons, E., Malde, B., Mesnard, A., Vera-Hernandez, M., 2016. Nutrition, information and household behavior: experimental evidence from Malawi. J. Dev. Econ. 122, 113-126.

Gowani, S., Yousafzai, A.K., Armstrong, R., Bhutta, Z.A., 2014. Cost effectiveness of responsive stimulation and nutrition interventions on early child development outcomes in Pakistan. Ann. N. Y. Acad. Sci. 1308 (1), 149-161.

Grantham-McGregor, S.M., Cheung, Y.B., Cueto, S., Glewwe, P., Richter, L., Strupp, B., International Child Development Steering Group, 2007. Developmental potential in the first 5 years for children in developing countries. The Lancet 369 (9555), 60-70.

Grantham-McGregor, S.M., Fernald, L.C., Kagawa, R., Walker, S., 2014. Effects of integrated child development and nutrition interventions on child development and nutritional status. Ann. N. Y. Acad. Sci. 1308 (1), 11-32.

Hamadani, J.D., Mehrin, S.F., Tofail, F., Hasan, M.I., Huda, S.N., Baker-Henningham, H., ... Grantham-McGregor, S.M., 2019. Integrating an early childhood development programme into Bangladeshi primary health-care services: an open-label, cluster randomised controlled trial. Lancet Glob. Health 7 (3), e366-e375.

Haque, M.R., Parr, N., Muhidin, S., 2019. Parents' healthcare-seeking behavior for their children among the climate-related displaced population of rural Bangladesh. Soc. Sci. Med. 226, 9-20.
Heckman, J.J., 2013. Giving Kids a Fair Chance. MIT Press, Cambridge, MA.

Heckman, J.J., Kautz, T., 2014. Fostering and measuring skills: interventions that improve character and cognition. In: Heckman, J.J. (Ed.), The GED Myth: Education, Achievement Tests, and the Role of Character in American Life. Univ. Chicago Press, Chicago, IL, pp. 341-430.

Hurley, K.M., Yousafzai, A.K., Lopez-Boo, F., 2016. Early childhood development and nutrition: a review of the benefits and challenges of implementing integrated interventions. Adv. Nutr. 7 (2), 357-363.

Lassi, Z.S., Zahid, G.S., Das, J.K., Bhutta, Z.A., 2013. Impact of complementary food and education on complementary food on growth and morbidity of children less than 2 years of age in developing countries: a systematic review. BMC Public Health 13 (Suppl. 3), S13.

Lei, L., 2017. The impact of community context on children's health and nutritional status in China. Soc. Sci. Med. 179, 172-181.

Luby, S.P., Rahman, M., Arnold, B.F., Unicomb, L., Ashraf, S., Winch, P.J., ... Leontsini, E., 2018. Effects of water quality, sanitation, handwashing, and nutritional interventions on diarrhoea and child growth in rural Bangladesh: a cluster randomised controlled trial. Lancet Glob. Health 6 (3), e302-e315.

Luo, R., Shi, Y., Zhou, H., Yue, A., Zhang, L., Sylvia, S., ... Rozelle, S., 2014. Anemia and feeding practices among infants in rural Shaanxi Province in China. Nutrients 6 (12), 5975-5991.

Luo, R., Shi, Y., Zhou, H., Yue, A., Zhang, L., Sylvia, S., ... Rozelle, S., 2015. Micronutrient deficiencies and developmental delays among infants: evidence from a cross-sectional survey in rural China. BMJ Open 5 (10), e008400.

Luo, R., Yue, A., Zhou, H., Shi, Y., Zhang, L., Martorell, R., ... Sylvia, S., 2017. The effect of a micronutrient powder home fortification program on anemia and cognitive outcomes among young children in rural China: a cluster randomized trial. BMC Public Health 17 (1), 738.

McEwan, P.J., 2012. Cost-effectiveness analysis of education and health interventions in developing countries. J. Dev. Eff. 4 (2), 189-213.

Mistry, K.B., Minkovitz, C.S., Riley, A.W., Johnson, S.B., Grason, H.A., Dubay, L.C., Guyer, B., 2012. A new framework for childhood health promotion: the role of policies and programs in building capacity and foundations of early childhood health. Am. J. Public Health 102 (9), 1688-1696.

Noure, F.M., Reid, B.M., Humphrey, J.H., Mbuya, M.N., Pelto, G., Stoltzfus, R.J., 2014. Water, sanitation, and hygiene (WASH), environmental enteropathy, nutrition, and early child development: making the links. Ann. N. Y. Acad. Sci. 1308 (1), 118-128.

Pérez-Escamilla, R., Moran, V.H., 2017. The role of nutrition in integrated early child development in the $21^{\text {st }}$ century: contribution form the Maternal and Child Nutrition journal. Matern. Child Nutr. 13, e12387.

Ran, T., Chattopadhyay, S.K., Hahn, R.A., Community Preventive Services Task Force, 2016. Economic evaluation of school-based health centers: a Community Guide systematic review. Am. J. Prev. Med. 51 (1), 129-138.

Rao, N., Sun, J., Wong, J.M.S., Weekes, B., Ip, P., Shaeffer, S., ... Lee, D., 2014. Early Childhood Development and Cognitive Development in Developing Countries: a Rigorous Literature Review. Department for International Development, London.

Richter, L.M., Daelmans, B., Lombardi, J., Heymann, J., Boo, F.L., Behrman, J.R., Bhutta, Z.A., 2017. Investing in the foundation of sustainable development: pathways to scale up for early childhood development. Lancet 389 (10064), 103-118.

Rubio-Codina, M., Araujo, M.C., Attanasio, O., Muñoz, P., Grantham-McGregor, S., 2016. Concurrent validity and feasibility of short tests currently used to measure early childhood development in large scale studies. PLoS One 11 (8), e0160962.

Seguin, M., Zarazúa, N.M., 2015. Non-clinical interventions for acute respiratory infections and diarrhoeal diseases among young children in developing countries. Trop. Med. Int. Health 20 (2), 146-169.

Soofi, S., Cousens, S., Iqbal, S.P., Akhund, T., Khan, J., Ahmed, I., ... Bhutta, Z.A., 2013 Effect of provision of daily zinc and iron with several micronutrients on growth and morbidity among young children in Pakistan: a cluster-randomised trial. Lancet 382 (9886), 29-40.

Sylvia, S., Shi, Y., Xue, H., Tian, X., Wang, H., Liu, Q., et al., 2015. Survey using incognito standardized patients shows poor quality care in China's rural clinics. Health Policy Plan. 30 (3), 322-333.

Sylvia, S., Warrinnier, N., Luo, R., Attanasio, O., Medina, A., Rozelle, S., 2018. In: From Quantity to Quality: Delivering a Home-Based Parenting Intervention through China's Family Planning Cadres (LICOS Discussion Paper No. 402), Retrieved from KU Leuven LICOS website: https://feb.kuleuven.be/drc/licos/publications/discussionpapers.

Tao, S.Y., Cheng, Y.L., Lu, Y., Hu, Y.H., Chen, D.F., 2013. Handwashing behavior among Chinese adults: a cross-sectional study in five provinces. Public Health 127 (7), 620-628.

Wang, L., Sun, Y., Liu, B., Zheng, L., Li, M., Bai, Y., ... Rozelle, S., 2018. Is infant/toddler anemia a problem across rural China? A mixed-methods analysis. Int. J. Environ. Res. Public Health 15 (9), 1825.

Wang, L., Liang, W., Zhang, S., Jonsson, L., Li, M., Yu, C., ... Luo, R., 2019. Are infant/ toddler developmental delays a problem across rural China? J. Comp. Econ. 47 (2), 458-469.

Yousafzai, A.K., Aboud, F., 2014. Review of implementation processes for integrated nutrition and psychosocial stimulation interventions. Ann. N. Y. Acad. Sci. 1308 (1) $33-45$.

Yousafzai, A.K., Rasheed, M.A., Rizvi, A., Armstrong, R., Bhutta, Z.A., 2014. Effect of integrated responsive stimulation and nutrition interventions in the Lady Health Worker programme in Pakistan on child development, growth, and health outcomes: a cluster-randomised factorial effectiveness trial. The Lancet 384 (9950), 1282-1293.

Zelen, M., 1979. A new design for randomized clinical trials. N. Engl. J. Med. 300 (22), $1242-1245$. 